\title{
Seligman's flourishing: An appraisal of what lies beyond happiness
}

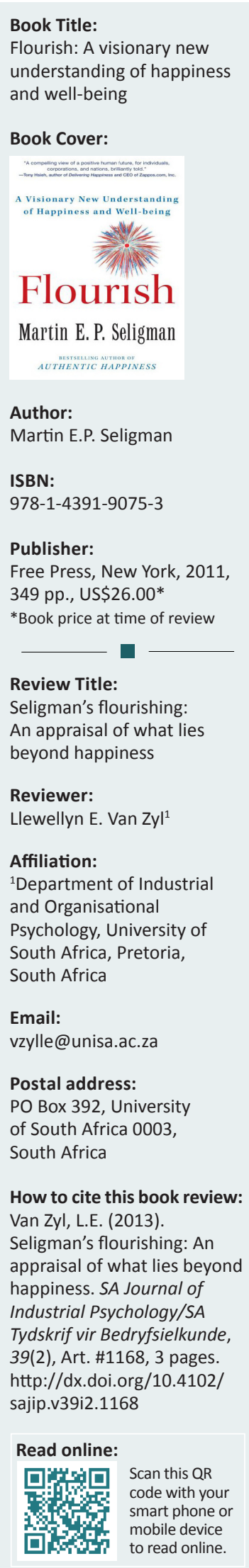

\section{Introduction}

Professor Martin Seligman is considered to be the most influential psychologist, researcher and author of modern times (Lyubomirsky, 2011; Van Zyl \& Du Toit, 2013). Many psychologists have labelled him as the 'father' of positive psychology (Lyubomirsky, 2011) based on his inaugural lecture as president of the American Psychological Association in 1998, in which he called for a more 'positive approach' towards understanding the domain of psychology (Wong, 2011b). According to Wong (2011a), Seligman's inaugural lecture focused on a call for understanding and investigating that which is 'good' or 'excellent' in human nature, or 'what makes happy people, happy'. This gave rise to Seligman's (2002) book Authentic happiness: Using the new positive psychology to realize your potential for lasting fulfilment, in which he argues that happiness is the result of living a 'pleasant', 'good' and 'meaningful life'.

This book (Seligman 2002) popularised the concept of human happiness in both the academic and self-help spheres. Since its publication in 2002, more than 7600 academic articles have been written on Seligman's conceptualisation of the topic. However, this approach received much critique from both practitioners and researchers (Sheldon, Kashdan \& Steger, 2011; Van Zyl \& Rothmann, 2012). Researchers argued that lasting happiness cannot be obtained merely through focusing on the philosophical paradigms and that more attention needs to be given to moderating factors influencing the experience (Wong, 2011a). Practitioners indicated that the effects of interventions structured around the approach are not sustainable (Van Zyl \& Du Toit, 2013). Seligman's response was a new book aimed at addressing the scientific concerns emanating from the critique and moving 'beyond happiness to understanding human flourishing'.

This new book, aptly titled Flourish: A visionary new understanding of happiness and well-being, was an attempt to comment on the critique of researchers and to build out his previous theory on the concept of happiness. The purpose of this review is to provide a brief report and evaluation of the scientific merits of Flourish.

\section{General overview}

The book follows a ten chapter structure similar to many mass market psychology texts. It starts with a general report on Seligman's new approach towards well-being, highlighting the historical developments in the field of positive psychology and concluding with his contribution to these progressions. Seligman (p. 26) argues that the goal of the book is to highlight the intended focus of positive psychology as a paradigm: 'to determine the contributors which enhances flourishing'.

The first chapter provides an introduction to Seligman's PERMA theory on human flourishing. This new theory builds upon the original conceptualisation of authentic happiness (comprised of pleasure, meaning and engagement) with two new additions: (1) positive relationships and (2) accomplishments. A brief attempt to conceptualise each component is presented in the first 30 pages of Flourish. This chapter briefly highlights the proposed components of the model and attempts to draw theoretical links between the variables and the concept of flourishing. In summation of this chapter, Seligman argues that the top end of human happiness or 'flourishing' is the result of the interaction and experience of PERMA:

\section{Positive emotion \\ Engagement in life and work \\ Positive Relationships \\ Meaning in life and work \\ Accomplishments}

The second and third chapters provide the reader with various approaches and applications of positive psychological interventions (PPIs) to enhance PERMA. These PPIs are regurgitations of a similar chapter in Peterson and Seligman (2004) as well as Seligman (2002) with no significant

Copyright: @ 2013. The Authors. Licensee: OpenJournals Publishing. This work is licensed under the Creative Commons Attribution License. 
new contributions. As with the majority of Seligman's work on PPIs, chapter 2 starts off with the Gratitude Visit, a selfadministered intentional activity aimed at displaying gratitude to an individual who has significantly positively impacted on one's life. Here, Seligman highlights the benefits of enhancing the experience of positive emotion in the past through the use of gratitude. The gratitude visit has become one of the focal interventions in PPI research as it has been shown to have a profound effect on the sustainability of the experience of positive emotion (Lyubomirsky, 2011; Sin \& Lyubomirsky, 2009; Van Zyl \& Rothmann, 2012). Further, Seligman briefly touches on other self-administered intentional activities structured around the utilisation and optimisation of signature strengths which have shown to have impacted on the development of sustainable happiness. These sections are paraphrased versions of chapters in Peterson and Seligman (2004).

Chapter 3 distinguishes between the effects of PPIs and the use of medication to enhance positive affect. The chapter summarises the work of Lyubomirsky (2007) on the hedonic treadmill and highlights various experiments on the relationship between pain tolerance and happiness. Seligman indicates that individuals with high levels of happiness are able to endure more physical pain, than their unhappy counterparts. Here, he also discusses the benefits of the experience of negative emotions and how medication manufacturers have structured a whole industry around the suffering of the masses.

The first three chapters of the book provide a good indication of the value of positive psychology and provide some evidence for PERMA. These chapters provide the layman with a satisfactory overview on the core components of flourishing and provide enough information to entice the reader to research the topic in more depth. However, the following seven chapters are structured around major contributions to the development of positive psychology as a practice field and Seligman's influence on and contribution to each event. It also highlights how shadow government organisations provided funding for research and how Seligman's (not positive psychology's) influence has stretched across the globe (Wong, 2013).

Chapter 4 and Chapter 5 provide an overview of Seligman's (2004) article 'Can happiness be taught?' in which he discusses the challenges he faced in his attempt to develop and present a master's program in Applied Positive Psychology (MAPP). These chapters also highlight two programmes that were developed and implemented in the US military and Geelong Grammar School to enhance positive emotion and build resilience. Limited attention is given to the techniques, interventions and approaches applied during these projects.

Chapters 6 through 8 focus on projects developed and implemented in the military. Again, the focus is on Seligman's involvement in the development of the projects and how funding was provided. These chapters make for fascinating reading 'only if one is interested in entering into the mind and heart of a brilliant psychologist, introducing its readers to the fairy-tale world of big money, big science, and big names, and Seligman's mega projects' (Wong, 2013). Each chapter does, however, provide a brief self-administered intentional activity which can be used to develop resilience, enhance physical fitness and to build self-regulation.

Chapter 9 provides an indication of the physical benefits of optimism and the effects an intervention program had within the US army. It further substantiates the utilisation of optimism as a means to combat physical diseases such as cardiovascular disease, cancer and infectious illnesses such as flu.

Finally, Chapter 10 focuses on the economics and politics of well-being. Here, Seligman attempts to argue that there is a theoretical relationship between the levels of happiness within a given country and their gross domestic product (GDP). The chapter also imagines a possible future in which positive psychology is integral to academic training programmes and highlights possible future research projects.

\section{Overall impression and conclusion}

In summation, the book opens with a philosophical attempt to provide context and substance to Seligman's new theory of well-being. It provides a shallow overview of theory and results in a personal monograph of Seligman's accomplishments, networks, funding and personal legacy. Further, the intended audience for the book is unclear as it is positioned neither as an academic publication nor as a popular psychology text. Little theoretical or empirical evidence is provided for the scientific substantiation of the proposed new theory of wellbeing. In fact, only three chapters of the 349-page manuscript attempt to build or explain the new theory. Yet some strengthenhancing activities and interventions are described which have been published by other authors (see Lyubomirsky, 2011). The book does not attempt to contribute any new or unique evidence-based interventions or approaches. Wong (2013) argues that the book should not be considered to be either an academic monograph or a popular psychology self-help book, but rather Seligman's personal account of the development of positive psychology.

At various instances in the book, Seligman argues that PERMA differs significantly from other theories and should be considered as the 'gold standard for measuring well-being' (p. 13), yet he fails to provide solid theoretical arguments or empirical evidence in support. Further, the presented theory, PERMA, is not significantly different from authentic happiness theory, but is rather repackaged and recycled with basic principles of consumer behaviour. Similarly, Seligman makes various inferences that PERMA is rooted in scientific evidence and that it is underpinned by signature strengths research. Yet, up to August 2013, no empirical research could be found to substantiate this argument. However, Seligman has initiated a large-scale project through AuthenticHappiness.org to develop and validate a measure for assessing flourishing within the United States. 
In conclusion, for the seasoned academic and practitioner, Flourish is a disappointment as a scholarly manuscript and as a pop psychology book. It does not significantly contribute to the current body of knowledge on human flourishing nor does it provide a comprehensive overview of the concept. The book lacks the vigour and sophistication that is to be expected of a scientist of Seligman's standing. Further, the book does not provide enough practical application to be considered a 'self-help' book as much of the text is autobiographic in nature and not a 'step-by-step' or 'how-to' guide on achieving flourishing (Wong, 2013). However, as an overview of major contributions to the field of positive psychology for the layman, and for Seligman's personal accounts thereof, this book is a definite 'must read'. This book is an decent companion for the first-year psychology student to provide a historical overview of positive psychology and to provide insight into what can be done with a career in psychology.

\section{References}

Lyubomirsky, S. (2007). The how of happiness: A scientific approach to getting the life you want. New York, NY: Penguin Press.
Lyubomirsky, S. (2011). The way to happiness: Action plan for a happy life. Or Yehuda, Israel: Kinneret Publishing House.

Peterson, C., \& Seligman, M.E.P. (2004). Character strengths and virtues: A handbook and classification. Washington, DC: American Psychological Association.

Seligman, M.E.P. (2002). Authentic happiness. New York, NY: Free Press.

Seligman, M.E.P. (2004). Can happiness be taught? Daedalus, 133(2), 80-87. http:// dx.doi.org/10.1162/001152604323049424

Sheldon, K., Kashdan, T., \& Steger, M. (Eds.). (2011). Designing the future of positive psychology: Taking stock and moving forward. New York, NY: Oxford University Press. psychology: Taking stock and moving forward. New York, NY: Oxford
http://dx.doi.org/10.1093/acprof:oso/9780195373585.001.0001

Sin, N.L., \& Lyubomirsky, S. (2009). Enhancing well-being and alleviating depressive symptoms with positive psychology interventions: A practice-friendly meta-analysis. Journal of Clinical Psychology: In Session, 65, 467-487. http://dx.doi.org/10.1002/ jclp.20593, PMid:19301241

Van Zyl, L.E., \& Du Toit, D. (2013, July). Carl Jung's contribution to positive organisational psychology. Research paper presented at the 15th Annual Society of Industrial / Organisational Psychologists in Conference, Pretoria, South Africa.

Van Zyl, L.E., \& Rothmann, S. (2012). Beyond smiling: The development and evaluation of a positive psychological intervention aimed at student happiness. Journal of Psychology in Africa, 22(3), 78-99.

Wong, P.T.P. (2011a). Positive psychology 2.0: Towards a balanced interactive model of the good life. Canadian Psychology, 52(2), 69-81. http://dx.doi.org/10.1037/ a0022511

Wong, P.T.P. (2011b). Reclaiming positive psychology: A meaning-centered approach to sustainable growth and radical empiricism. Journal of Humanistic Psychology, 34-41.

Wong, P.T.P. (2013). Big money, big science, big names and the flourishing of positive psychology. Retrieved August 21, 2013, from http://www.drpaulwong.com/index. psychology. Retrieved August 21,2013 , from http://www.drpaulwong.com/index.
php?option=com content\&view=article\&id=160:big-money-big-science-big-namesphp?option=com_content\&view=article\&id=160:big-money-big-science-big-names-
and-the-flourishing-of-positive-psychology\&catid=57:book-reviews\&ltemid=129 